\title{
The Total Face Mask Is More Comfortable than the Oronasal Mask in Noninvasive Ventilation but Is Not Associated with Improved Outcome
}

\author{
Fernando Hauaji Chacur ${ }^{\mathrm{a}}$ Luis Marcelo Vilella Felipe ${ }^{a}$ \\ Cintia Gonçalves Fernandes ${ }^{b}$ Luiz Claudio Oliveira Lazzarini ${ }^{a}$ \\ Departments of ${ }^{\mathrm{a}}$ Respiratory Disease and ${ }^{\mathrm{b}}$ Physical Therapy, Pro-Cardíaco Hospital, Rio de Janeiro, Brazil
}

\section{Key Words}

Noninvasive positive-pressure ventilation - Total face mask • Oronasal mask

\section{Abstract}

Background: Noninvasive positive-pressure ventilation (NPPV) is commonly used to improve ventilation and oxygenation and avoid endotracheal intubation and mechanical ventilation. Although clinically indicated, most patients fail to use NPPV due to mask intolerance. A total face mask was designed to increase compliance, but whether this translates into better outcome (improvement in clinical and blood gas parameters and less intubation) is unknown. $\mathbf{O b}$ jectives: We compared the evolution of the clinical parameters, blood gases, levels of ventilatory support and rate of endotracheal intubation using the total face mask or the traditional oronasal mask during NPPV. Methods: A total of 60 patients were randomized to use either mask during NPPV. The clinical and laboratory parameters, as well as the level of ventilatory support were recorded at different intervals in both groups for up to $6 \mathrm{~h}$. In addition, the tolerance for each mask and the need for endotracheal intubation were com- pared. Results: Patients tolerated the total face mask significantly better $(p=0.0010)$ and used NPPV for a longer time $(p=0.0017)$ when compared with the oronasal mask. Just 1 patient switched to the total face mask because of intolerance. Although better tolerated, the rate of endotracheal intubation was similar in both groups $(p=0.4376)$, as was the clinical and laboratory evolution. Conclusions: The total face mask was more comfortable, allowing the patients to tolerate NPPV longer; however, these accomplishments did not translate into a better outcome. Due to its comfort, the total face mask should be available, at least as an option, in units where NPPVs are routinely applied.

Copyright $\odot 2011$ S. Karger AG, Basel

\section{Introduction}

In the last decade, there has been an increased use of noninvasive positive-pressure ventilation (NPPV) in patients with respiratory failure. There are several advantages of NPPV over endotracheal intubation and invasive ventilation, such as fewer incidences of nosocomial pneumonia and laryngeal stenosis, as well as a decrease

\section{KARGER}

Fax +4161306 1234

E-Mail karger@karger.ch

www.karger.com (c) $2011 \mathrm{~S}$. Karger AG, Basel

0025-7931/11/0825-0426\$38.00/0

Accessible online at:

www.karger.com/res
Fernando H. Chacur

Rua General Polidoro 192

Botafogo, Rio de Janeiro 22280-003 (Brazil)

Tel. +55 2125281411

E-Mail aventilatoria@ procardiaco.com.br 
in the length of hospital stay and even mortality $[1,2]$. The major indications of NPPV are the treatment of acute exacerbations of patients with chronic obstructive pulmonary disease or as an auxiliary method in their weaning from invasive ventilation, acute cardiogenic pulmonary edema and lung infection resulting in respiratory failure in immunosuppressed patients [3-8]. In addition, NPPV can also be helpful in hypoxemic respiratory failure, in the prevention of post-extubation respiratory failure and in selected cases of acute asthmatic attacks $[9,10]$. Although clinically indicated, some patients do not tolerate the mask interface or the clinical conditions deteriorate despite its use, eventually leading to intubation. As a matter of fact, about a third of patients fail to tolerate NPPV $[11,12]$, and the main reasons for this intolerance are air leaks around the mask, claustrophobia and facial discomfort. To overcome these problems, new masks have been designed to increase the comfort while maintaining a tight seal necessary for this kind of ventilation. Although the nasal mask is usually considered better tolerated than the oronasal mask, the occurrence of buccal air leaks frequently precludes its use and resulted in the modification of the mask [13]. For this reason, it has been suggested that the oronasal mask should be the initial first choice in the management of acute respiratory failure [13], although this is still controversial $[14,15]$.

To further increase patient compliance, a total face mask that covers the whole face was developed [16] and promised to be an attractive alternative to the other masks. Surprisingly, there is a paucity of studies exploring this new mask $[16,17]$ and whether a more comfortable mask ultimately results in better outcomes and reduces the rate of endotracheal intubation and its consequences is still undefined.

To address these questions, we compared the outcomes of patients requiring NPPV using either the oronasal or the total face mask.

\section{Patients and Methods}

\section{Study Population}

The study was conducted at Pro-Cardíaco Hospital, a private hospital with 40 intensive or semi-intensive beds, primarily attending cardiac and pulmonary diseases. Inclusion criteria were the development of respiratory failure caused by any condition where NPPV was indicated. To be eligible, the patients had to have dyspnea and at least one of the following: tachypnea (respiratory rate $>24 / \mathrm{min}$ ); use of accessory muscles of respiration, paradoxal breathing; $\mathrm{pH}<7.35$ with no other explanation; $\mathrm{PaCO}_{2}>45 \mathrm{~mm}$
$\mathrm{Hg}$ or a $\mathrm{PaO}_{2} / \mathrm{FiO}_{2}<250$ at room air. Exclusion criteria were patients with altered mental status, excessive respiratory secretion, unstable coronary disease, cardiac arrhythmia leading to circulatory instability, arterial hypotension (systolic pressure $<90 \mathrm{~mm}$ $\mathrm{Hg}$ or decreasing more than $40 \mathrm{~mm} \mathrm{Hg}$ from baseline), abnormal coagulation (international normalized ratio $>2$, platelet count $<60,000$ ), extensive facial lesions, facial trauma, upper airway obstruction, recent upper airway, esophagus or stomach surgery, or a medical condition requiring immediate endotracheal intubation.

Patients were randomized to receive NPPV via either an oronasal or a total face mask (Respironics Inc., Murrysville, Pa., USA). Randomization was performed in advance by a third party who tossed a coin (head - total face mask, tail - oronasal mask), then sealed and sequentially numbered all the envelopes including the mask options. The researchers were blinded to these options and only when the patients were enrolled in the study were the researchers allowed to open the envelopes. The study was approved by the local ethics committee.

\section{NPPV Technique}

NPPV was performed and monitored by a respiratory therapist under the supervision of the attending physician. NPPV was performed using the ventilator Knightstar 335 (Puritan Bennett, Pleasanton, Calif., USA). The NPPV settings were in accordance with established guidelines [18]. In general, NPPV was applied continuously for up to $6 \mathrm{~h}$, starting with an inspiratory positive airway pressure (IPAP) of $4 \mathrm{~cm} \mathrm{H}_{2} \mathrm{O}$ and an expiratory positive airway pressure (EPAP) of $4 \mathrm{~cm} \mathrm{H}_{2} \mathrm{O}$. The levels were raised $1 \mathrm{~cm}$ $\mathrm{H}_{2} \mathrm{O}$ every $3 \mathrm{~min}$, as necessary. Supplementary oxygen from 3 to $15 \mathrm{l} / \mathrm{min}$ was added to reach an arterial oxygen saturation $\left(\mathrm{SpO}_{2}\right)$ $>90 \%$. Airtight application of the mask was achieved by elastic straps. The mask was first applied manually and then secured to the face using the straps. Skin irritation was prevented by routinely applying colloids onto the nasal bridge. All patients underwent continuous noninvasive systemic arterial blood pressure, $\mathrm{SpO}_{2}$ and electrocardiogram monitoring. The ventilatory parameters (respiratory rate, tidal volume, flow, IPAP and EPAP, airway leak and I:E ratio) were recorded as displayed by the ventilator. The NPPV weaning process followed the guidelines described elsewhere [18].

\section{Variables}

At inclusion, epidemiological (age, gender) and clinical (blood pressure, pulse rate, respiratory rate, use of accessory muscles of respiration) data were recorded, along with noninvasive measurement of $\mathrm{SpO}_{2}$ at room air and with supplemental oxygen. The clinical parameters were reviewed after $30 \mathrm{~min}$, and then at 1-, 2-, 4- and 6-hour intervals after initiation of NPPV. During each time period, the clinical parameters, levels of ventilatory support (IPAP and EPAP) and the amount of supplemental oxygen were recorded. A visual scale of mask comfort was applied to the patients and graded as $1-5$, where 1 was very comfortable and 5 was very uncomfortable. The primary end points were compliance with the mask, total time of NPPV and the requirement of endotracheal intubation within each mask group. Secondary end points were the need to switch the mask and the evolution of the clinical and arterial blood gas (ABG) parameters. 
Table 1. Epidemiological, clinical and ABG parameters of both mask groups at initiation of therapy

\begin{tabular}{lcll}
\hline Parameters & $\begin{array}{l}\text { Oronasal } \\
\text { mask }\end{array}$ & $\begin{array}{l}\text { Total } \\
\text { face mask }\end{array}$ & $\begin{array}{l}\mathrm{p} \\
\text { value }\end{array}$ \\
\hline Gender (M/F), \% & $38 / 62$ & $53 / 47$ & 0.1142 \\
Age, years & $79 \pm 9$ & $77 \pm 11$ & 0.2603 \\
Respiratory rate/min & $32 \pm 7$ & $31 \pm 6$ & 0.7089 \\
Heart rate/min & $91 \pm 16$ & $94 \pm 23$ & 0.6545 \\
Use of accessory & & & \\
$\quad$ respiratory muscle, \% & $21(\mathrm{n}=34)$ & $19(\mathrm{n}=26)$ & 0.3570 \\
$\mathrm{SpO}_{2}$ at admission, room air, \% & 85 & 83 & 0.5296 \\
$\mathrm{SpO}_{2}$ at admission, & & & \\
$\quad$ after supplemental $\mathrm{O}_{2}, \%$ & 92 & 90 & 0.6140 \\
$\mathrm{ABG}^{\mathrm{pH}}$ & & & \\
$\quad \mathrm{PCO}_{2}, \mathrm{~mm} \mathrm{Hg}$ & $4.35 \pm 0.1$ & $7.34 \pm 0.10$ & 0.3687 \\
$\quad \mathrm{PO}_{2}, \mathrm{~mm} \mathrm{Hg}$ & $97 \pm 46$ & $43 \pm 14$ & 0.4923 \\
$\mathrm{HCO}, \mathrm{mmol} / \mathrm{l}$ & $22 \pm 4$ & $22 \pm 6$ & 0.3355 \\
$\quad \mathrm{BE}, \mathrm{mmol} / \mathrm{l}$ & $3 \pm 2$ & $5 \pm 4$ & 0.060 \\
$\mathrm{Lactate}, \mathrm{mmol} / \mathrm{l}$ & $2.1 \pm 1$ & $1.6 \pm 0.9$ & 0.4947 \\
\hline
\end{tabular}

$\mathrm{M}=$ Male; $\mathrm{F}=$ female $\mathrm{BE}=$ base excess.
Table 2. Comparison of compliance, total time of NPPV use and need of tracheal intubation with both masks

\begin{tabular}{lccc}
\hline Parameters & $\begin{array}{l}\text { Oronasal } \\
\text { mask }\end{array}$ & $\begin{array}{l}\text { Total } \\
\text { face mask }\end{array}$ & $\begin{array}{l}\mathrm{p} \\
\text { value }\end{array}$ \\
\hline Compliance, \% of users & 46 & 87 & 0.0010 \\
Total time, min & $178 \pm 141$ & $288 \pm 126$ & 0.0017 \\
Need of tracheal intubation, \% & 17 & 19 & 0.4376 \\
\hline
\end{tabular}

Table 3. ABG parameters after $1 \mathrm{~h}$ of NPPV in both mask groups

\begin{tabular}{lcccc}
\hline & $\begin{array}{l}\text { Oronasal } \\
\text { mask }\end{array}$ & $\mathrm{p}$ value & $\begin{array}{l}\text { Total } \\
\text { face mask }\end{array}$ & $\mathrm{p}$ value \\
\hline $\mathrm{pH}$ & $7.37 \pm 0.04$ & 0.0864 & $7.38 \pm 0.05$ & 0.0516 \\
$\mathrm{PCO}_{2}, \mathrm{~mm} \mathrm{Hg}$ & $41 \pm 11$ & 0.2892 & $39 \pm 10$ & 0.1478 \\
$\mathrm{PO}_{2}, \mathrm{~mm} \mathrm{Hg}$ & $115 \pm 69$ & 0.1626 & $110 \pm 52$ & 0.1023 \\
$\mathrm{HCO}_{3}, \mathrm{mmol} / \mathrm{l}$ & $21 \pm 6$ & 0.2946 & $23 \pm 5$ & 0.3755 \\
$\mathrm{BE}, \mathrm{mmol} / \mathrm{l}$ & $5 \pm 5$ & 0.0886 & $3 \pm 3$ & 0.0764 \\
\hline
\end{tabular}

Statistical analysis comparing the evolution of the blood gases before initiation of therapy and $1 \mathrm{~h}$ after therapy was implemented in each mask group. $\mathrm{BE}=$ base excess.

collected at admission. Measurement of ABG was repeated after $1 \mathrm{~h}$ of NPPV in $66 \%$ of patients $(\mathrm{n}=40)$. Despite better toleration and longer NPPV use in the total face mask group, the decrease in the respiratory and heart rates and the amount of pressure support (IPAP and EPAP) were similar in both groups as was the improvement in ABG (table 3). In relation to endotracheal intubation, 4 patients (15\% of total) in the total face mask group were eventually intubated due to the worsening of the medical condition, compared to 6 patients (17\% of total) in the oronasal mask group, and this difference was not statistically significant $(\mathrm{p}=0.4376)$. Interestingly, all patients that needed endotracheal intubation in the total face mask group tolerated the mask during the whole time, compared with only 2 out of the 6 patients in the oronasal mask group.

\section{Discussion}

NPPV has become an important instrument in the emergency and intensive care wards, giving respiratory support, while other therapies are implemented to reverse respiratory failure. With this approach, patients are spared intubation and mechanical ventilation. In 
some situations, its role as first-line support ventilation is solid whereas in others, a trial may be worthwhile before proceeding to tracheal intubation, as long as there is no contraindication. Although widely available, NPPV is underused even among patients with chronic obstructive pulmonary disease exacerbations and cardiogenic pulmonary edema, the 2 best and widely accepted indications [19]. One of the main reasons for NPPV failure is intolerance of the mask, and for this reason, new masks were designed to overcome this problem, including the total face mask and the helmet. Both are recommended for patients with claustrophobia, and additionally allow the patient to talk and read while decreasing some complications such as eye irritation and skin necrosis $[20,21]$. Although an interesting interface, the helmet is more difficult for the physical therapist or other health care providers to handle, may accumulate carbon dioxide and may cause hearing damage due to the noise exposure inside the helmet [21-23]. Some of these drawbacks are not shared by the total face mask. Furthermore, the helmet was associated with worse patient-ventilator synchrony and inspiratory effort when compared with the oronasal mask [21]. For these reasons, the total face mask is probably the best tolerated mask and may be an attractive alternative in cases where mask intolerance is the primary reason for failing to comply with NPPV. This is in accordance with our results which showed that the total face mask was more comfortable for the patients, resulting in longer use of NPPV, when compared with the oronasal mask. As it is believed that patients who have a favorable response to NPPV usually improve within the first $2 \mathrm{~h}[24,25]$, it is extremely important that patients tolerate the mask as long as necessary to correct the respiratory failure while specific therapies are being implemented. For this reason, the better tolerated total face mask might theoretically be an advantage and results in less intubation, when compared with the (less pleasant) oronasal mask. However, our results did not show any difference in the clinical and $A B G$ results or in the rate of intubation. One possible explanation is that an even larger population would be necessary to show any statistical difference. Another explanation is that there is really no difference at all, and the use of different masks is only a matter of patient comfort and costs. As all patients in the total face mask group who were eventually intubated tolerated the mask while most in the oronasal mask group did not, it seems suitable as a first option. We hope that more studies are conduct with an even larger population. In conclusion, the total face mask is an attractive mask that increases compliance and should be available, at least as an option, in units where NPPV is routinely applied. Although not established to improve the final outcome, its comfort and easy use are at least very positive for both the patients and health professionals.

\section{References}

1 Demoule A, Girou E, Richard JC, Taille S, Brochard L: Benefits and risks of success or failure of noninvasive ventilation. Intensive Care Med 2006;32:1756-1765.

$\checkmark 2$ Hess DR: Noninvasive positive-pressure ventilation and ventilator-associated pneumonia. Respir Care 2005;50:924-929.

-3 Liesching T, Kwok H, Hill NS: Acute applications of noninvasive positive pressure ventilation. Chest 2003;124:699-713.

4 Celikel T, Sungur M, Ceyhan B, Karakurt S: Comparison of noninvasive positive-pressure ventilation with standard medical therapy in hypercapnic acute respiratory failure. Chest 1998;114:1636-1642.

5 Antonelli M, Conti G, Rocco M, Bufi M, De Blasi RA, Vivino G, Gasparetto A, Meduri GU: A comparison of noninvasive positivepressure ventilation and conventional mechanical ventilation in patients with acute respiratory failure. N Engl J Med 1998;339: 429-435.
6 Celikel T, Sungur M, Ceyhan B, Karakurt S: Medical therapy in hypercapnic respiratory failure. Chest 1998;114:1636-1642.

-7 Hilbert G, Gruson D, Vargas F, Valentino R, Gbikpi-Benissan G, Dupon M, Reiffers J, Cardinaud JP: Noninvasive ventilation in immunosuppressed patients with pulmonary infiltrates, fever, and acute respiratory failure. N Engl J Med 2001;344:481-487.

-8 Antonelli M, Conti G, Bufi M, Costa MG, Lappa A, Rocco M, Gasparetto A, Meduri GU: Noninvasive ventilation for treatment of acute respiratory failure in patients undergoing solid organ transplantation: a randomized trial. JAMA 2000;283:235-241.

-9 Barreiro TJ, Gemmel DJ: Noninvasive ventilation. Crit Care Clin 2007;23:201-222.

10 Soroksky A, Stav D, Shpirer I: A pilot prospective, randomized, placebo-controlled trial of bilevel positive airway pressure in acute asthmatic attack. Chest 2003;123: 1018-1025.
11 Karnik AM: Noninvasive positive pressure ventilation: testing the bridge. Chest 2000; 117:625-627.

12 Antonelli M, Conti G, Moro ML, Esquinas A, Gonzalez-Diaz G, Confalonieri M, Pelaia P, Principi T, Gregoretti C, Beltrame F, Pennisi MA, Arcangeli A, Proietti R, Passariello M, Meduri GU: Predictors of failure of noninvasive positive pressure ventilation in patients with acute hypoxemic respiratory failure: a multi-center study. Intensive Care Med 2001; 27:1718-1728.

$\checkmark 13$ Girault C, Briel A, Benichou J, Hellot MF, Dachraoui F, Tamion F, Bonmarchand G: Interface strategy during noninvasive positive pressure ventilation for hypercapnic acute respiratory failure. Crit Care Med 2009;37: 124-131.

14 Kwok H, McCormack J, Cece R, Houtchens J, Hill NS: Controlled trial of oronasal versus nasal mask ventilation in the treatment of acute respiratory failure. Crit Care Med 2003;31:468-473. 
15 Navalesi P, Fanfulla F, Frigerio P, Gregoretti C, Nava S: Physiologic evaluation of noninvasive mechanical ventilation delivered with three types of masks in patients with chronic hypercapnic respiratory failure. Crit Care Med 2000;28:1785-1790.

-16 Criner GJ, Travaline JM, Brennan KJ, Kreimer DT: Efficacy of a new full face mask for noninvasive positive pressure ventilation. Chest 1994;106:1109-1115.

17 Roy B, Cordova FC, Travaline JM, D’Alonzo GE Jr, Criner GJ: Full face mask for noninvasive positive-pressure ventilation in patients with acute respiratory failure. J Am Osteopath Assoc 2007;107:148-156.

18 International Consensus Conferences in Intensive Care Medicine: Noninvasive positive pressure ventilation in acute respiratory failure. Am J Respir Crit Care Med 2001;163: 283-291.
19 Sweet DD, Naismith A, Keenan SP, Sinuff T, Dodek PM: Missed opportunities for noninvasive positive pressure ventilation: a utilization review. J Crit Care 2008;23:111-117.

20 Navalesi P, Fanfulla F, Frigerio P, Gregoretti C, Nava S: Physiologic evaluation of noninvasive mechanical ventilation delivered with three types of masks in patients with chronic hypercapnic respiratory failure. Crit Care Med 2000;28:1785-1790.

21 Navalesi P, Costa R, Ceriana P, Carlucci A, Prinianakis G, Antonelli M, Conti G, Nava $S$ : Non-invasive ventilation in chronic obstructive pulmonary disease patients: helmet versus facial mask. Intensive Care Med 2007; 33:74-81.

22 Cavaliere F, Conti G, Costa R, Proietti R, Sciuto A, Masieri S: Noise exposure during noninvasive ventilation with a helmet, a nasal mask, and a facial mask. Intensive Care Med 2004;30:1755-1760.
23 Patroniti N, Foti G, Manfio A, Coppo A, Bellani G, Pesenti A: Head helmet versus face mask for non-invasive continuous positive airway pressure: a physiological study. Intensive Care Med 2003;29:1680-1687.

24 Antón A, Güell R, Gómez J, Serrano J, Castellano A, Carrasco JL, Sanchis J: Predicting the result of noninvasive ventilation in severe acute exacerbations of patients with chronic airflow limitation. Chest 2000;117: 828-833.

25 Soo Hoo GW, Santiago S, Williams AJ: Nasal mechanical ventilation for hypercapnic respiratory failure in chronic obstructive pulmonary disease: determinants of success or failure. Crit Care Med 1994;22:1253-1261. 